\title{
From community to clients: the professionalisation of HIV prevention among gay men and its implications for intervention selection
}

\section{Wohlfeiler}

Forces at work are described which encourage professionalisation and a reliance on one on one HIV prevention interventions among gay men. Community involvement is intrinsically linked to epidemic phases; when the threat diminishes, so does the community's ability to sustain community level interventions. The area of structural and environmental interventions, which can reinforce safe behaviour when community interest in collective action wanes, provides a potential complementary solution for prevention workers, researchers, and funders alike.

"Take another leaf out of the smoking story; set about building a social movement in a conscious and purposeful way. Such movements involve alliances between grass-roots and official forces. Public health agencies need first to define the nature of the threat and then to publicise appropriate measures. With all else equal, understanding will first reach those most conscious of the threat and then become diffused. As momentum builds, all levels of the movement must engage with public polity, press hard on official agencies, and advocate legislation and regulation as needed." Susser M. In: American Journal of Public Health 1996;86:1713-16.

"I have discovered that whenever I hear the statement, 'if we only save one person, it will be worthwhile,' I am listening to the definition of a failing program." Worden M. In: Journal of Drug Issues 1979;3:42533.

\section{THE DRIFT TO ONE ON ONE INTERVENTIONS}

Towards the end of 1981, in San Francisco, a registered nurse named Bobbi Campbell became the first Kaposi's sarcoma patient to go public in a column in one of San Francisco's gay newsweeklies, the Sentinel. ${ }^{1}$ A few weeks later, he convinced the local drugstore at the corner of 18th and Castro to put up posters with warnings about new cases of Kaposi's sarcoma. In New York, gay activists held their first fundraiser for "gay cancer." These were AIDS prevention's first efforts, and examples of grassroots community organising, accessing media, and peer education.
In 1996, just after the International AIDS Conference in Vancouver, Canada, leaders of the six largest US AIDS prevention programmes for gay men met to compare programmes, exchange strategies, and reflect on next steps while facing the first days of new and promising treatments. There were two remarkable things about this meeting. First, it hadn't happened before. Second, while their programmes had once boasted substantial community involvement, four of the six could now count on just a handful of volunteers. Several of the programmes had begun prevention case management programmes, with varying degrees of success in attracting clients. Instead of participants, programme managers referred to clients; instead of working within and with their communities, they worried about whether they were culturally appropriate for their "target populations."

In those 15 years, the gay community had dramatically reduced its risky behaviour. ${ }^{2}$ Most of that behaviour change took place before and as the community created its own organisations to continue those efforts (see fig 1). Since then, the community had largely delegated the problem of HIV prevention to those organisations. The agencies, in turn, had largely accepted responsibility for both the problem of new infections and the programmatic solutions to attempt to reduce them.

In other areas of public health, and to a lesser extent in HIV, there is a growing recognition of the need to move towards broad based community level interventions and even structural and environmental interventions. ${ }^{3-6}$ Yet the gay community's AIDS prevention efforts had drifted down a path of increasing emphasis on one on one interventions.

This paper seeks to help understand the reasons for this drift and its implications for how we choose interventions. How did it happen? Is it irreversible? How did the evolution of the epidemic affect that drift? How much was the community involved in HIV prevention in the first place, and how involved is it today? Most importantly, how should the balance of interventions change as the epidemic moves through different phases?

I will argue that community involvement is intrinsically related to epidemic phases; when the threat diminishes, so does the community's ability to sustain community level interventions. When that happens, planners and communities need to make strategic choices. They can choose to place a greater emphasis on individual level or "downstream" interventions such as counselling or prevention case management. Alternatively, 


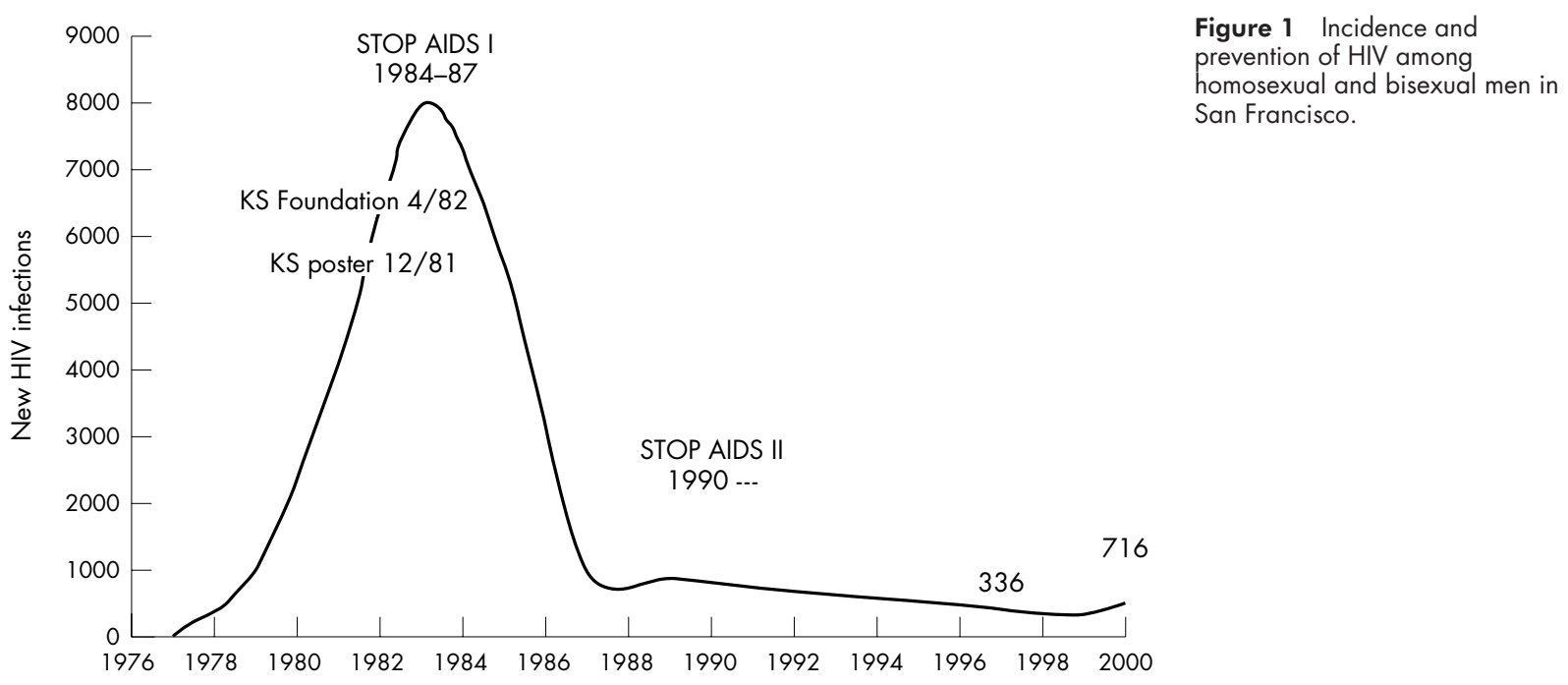

they can choose to move "upstream" towards community level and environmental interventions.

Owing to various forces which I will describe in this paper, programme planners' and educators' strategies became more and more downstream. I will also argue that this is the wrong direction. This emphasis, given the limited resources available to HIV prevention, threatens a balanced approach to interventions, which has the greatest potential to reduce infections, particularly in areas of high prevalence. While these forces are powerful, there are specific strategies which government, funders, and community based organisations have used, and may continue to use, to resist them. In conclusion, I will provide some practical suggestions for how funders and practitioners may explicitly confront and address them to assure a broader spectrum of interventions.

\section{GAY MALE HIV PREVENTION AS THE POTENTIAL HIGH WATER MARK}

The gay community in San Francisco is well recognised for its rapid decrease in risk behaviour which resulted in a decrease in incidence. Most of the behaviour change took place very quickly, and to a large degree was simultaneous with the establishment of AIDS prevention agencies, rather than a result of those efforts. It is incumbent upon us as practitioners and researchers to examine that mobilisation's ingredients critically and replicate as many steps as are possible. As this paper will lay out, that mobilisation was very brief, and few organisations took it upon themselves to maintain that mobilisation's momentum.

In contrast to anywhere else in the USA, gay men (including gay male injection drug users) in San Francisco continue to make up $85 \%$ of all living AIDS $\operatorname{cases}^{6 a}$ and $85 \%$ of new infections. ${ }^{7}$ In San Francisco in particular, by the time AIDS first appeared, the gay community had achieved important political successes. Gay men and lesbians and their allies had achieved high ranks throughout city government and they had important positions-and allies_-in the health department.

Perhaps most importantly, in contrast to virtually all other local AIDS epidemics, the HIV epidemic in San Francisco was not linked to poverty. Compared with any other affected community in the globe, the gay community in San Francisco had more resources at its disposal than anywhere, and fewer competing needs that so often hamper community involvement in the USA and other countries. ${ }^{8}$ The massive, rapid, and disastrous levels of new infection, accessible resources, and a well developed political leadership all provided the key ingredients for a major social mobilisation.

All these ingredients clearly and obviously limit the generalisability of the San Francisco experience. This is what makes it so important. The gay community in San Francisco represents a potential high water mark of what is achievable in HIV prevention. For if a community with this level of threat and resources finds it difficult to mobilise itself and its resources to dedicate to HIV prevention, communities which face less of a threat and have fewer resources and more competing priorities will face even greater challenges. Simply put, if a community faces other severe competing health issues, poverty, crime, food, violence, or war, it is unreasonable to expect them to also participate actively in community efforts to prevent HIV.

\section{THE EPIDEMIOLOGY OF HIV AND SEXUALLY TRANSMITTED DISEASES IN SAN FRANCISCO'S GAY AND BISEXUAL MEN}

There are multiple detailed descriptions of the course of the epidemic in gay men in San Francisco. The epidemic hit so early on that the bulk of infections happened before, and just as, the community built its first prevention efforts in the early 1980s. These were quickly followed by a drop in infections. In the mid-1990s, at the same time as new treatments became available, risk behaviour began to climb, while interest in prevention activities declined. These increases in risk behaviours then triggered an increase in new infections.

\section{HIV incidence}

Currently, there are approximately 46800 gay men in San Francisco, ${ }^{9}$ who represent a significant portion of the city's entire population, estimated to be around 800000 .

HIV was present in the gay community as early as 1978. As illustrated in fig 1, rates of incidence rose as high as $18.4 \%$ by 1982 and fell to $1 \%$ by $1987 .{ }^{2}$ Based on these incidence methods and other calculations, it is estimated that 8000 new infections occurred in 1982. These numbers quickly fell to 500 in 1987 and further still to 336 by 1997. Since then, the incidence has risen to $2.2 \%{ }^{10}$

\section{HIV prevalence}

The initial high rates of incidence led to prevalence rates of $48.6 \%$ among gay and bisexual men by 1984 . $^{\circ}$ Prevalence gradually declined, and by 1992 it was estimated that $42 \%$ of local gay and bisexual men were HIV infected. Younger generations were hit less hard; a population based study of gay and bisexual men under 30 showed a prevalence of less than $17 \%$ in 1992. ${ }^{11}$ By 1997, the overall rate had declined further to $30 \%$, with lower rates (15\%) among men less than 30 years old, and higher rates $(35 \%)$ among gay and bisexual men who also injected drugs. By 2000, 27.3\% of gay and bisexual men were 
Table 1 Upstream and downstream units of analysis

Individual Counselling; prevention case management

Group Single and multiple session group workshops

Community Partnerships with key opinion leaders and private sector; paid and unpaid media; large scale outreach strategies

Environmental Laws and policies

estimated to be living with HIV, with $40 \%$ of gay and bisexual men who were also injection drug users being infected.'

\section{Gonorrhoeal proctitis}

Rates of gonorrhoeal proctitis declined dramatically from 5000 in 1980 to 4000 in 1982, and to just over 2000 in $1983 .{ }^{12}$ Rates continued to fall almost 50\% each year until 1987. By 1993, rates hit their lowest at 20 per 100000 adult men, and climbed back up to 38 per 100000 by 1997. This occurred at the same time as the increase in unprotected anal sex described below. ${ }^{13}$

\section{Behaviour change}

San Francisco is widely considered to be the site of one of the most remarkable reductions in risk behaviour in public health history. Risk behaviour decreased dramatically in the first years of the epidemic, stayed low for a decade, then gradually increased again, although to nowhere near the levels of earlier. The number of casual male partners decreased very rapidly, from 6.3 in November 1982 to 3.9 in May 1984. Frequency of receptive anal intercourse without a condom with casual partners declined from 1.7 to 0.7 times a month. ${ }^{14}$ Those who reduced risk more were younger, more likely to have seen someone in last stages of AIDS, believed in health guidelines, reported more perceived self efficacy, and had effective stress management strategies. ${ }^{15}$ Among seronegative men the prevalence of receptive anal intercourse with two or more partners declined from $15 \%$ in the first half of 1984 to $5 \%$ in the second half, and remained low through $1987 .{ }^{2}$

After the initial decreases in unprotected anal sex, this practice increased from $37 \%$ to $50 \%$ between 1993-94 and 1996-97, with almost half reporting with a partner of unknown or discordant HIV antibody status. ${ }^{15 a}$ Between 1994 and 1998, volunteers from the community based organisation STOP AIDS collected 26176 surveys from gay and bisexual men as part of their recruitment to other interventions. The proportion of gay and bisexual men reporting anal sex in the last six months increased from $58 \%$ in 1994 to $66 \%$ in 1998 , while the proportion reporting always using condoms with anal sex decreased from $70 \%$ to $58 \%$. The proportion of these men reporting unprotected anal sex and multiple partners increased from $24 \%$ in 1994 to $43 \%$ in $1999 .{ }^{9}$

\section{WHY ARE BROAD BASED INTERVENTIONS IMPORTANT?}

Practitioners in any field of public health may choose from a spectrum of available interventions. One simple way to describe these is as "downstream" and "upstream," with downstream interventions focusing on the individual and upstream on ever greater units of analysis (table 1).

While upstream interventions may have the greatest potential, they remain severely underutilised in HIV prevention, particularly among gay men. ${ }^{16}$ There are several key arguments to be made in favour of these broad based interventions, and why they are particularly suited to HIV prevention in gay men in urban settings.

First, broad based community level interventions are particularly important in epidemics of high prevalence. When risk is widely distributed in the population, as it is in San Francisco, small changes in behaviour observed across an entire population are likely to yield greater improvements in the population attributable risk than larger changes among a smaller number of high risk individuals. ${ }^{3}$

Second, upstream interventions-particularly structural and environmental interventions-have the potential to alter the physical environments and settings where mixing takes place, such as bathhouses, sex clubs in the gay community, ${ }^{6}$ or shooting galleries among injection drug users. Environmental interventions, while important, will not be this paper's focus.

In many fields of public health, early interventions are based on disseminating information and educational interventions. As it becomes clearer that these downstream interventions have a limited impact, structural interventions are proposed and eliminated. ${ }^{17}$ That time may now be upon us in HIV prevention.

Broad based interventions also have the potential to change social factors and alter the balance of power and resources that may reduce HIV transmission. ${ }^{18}$ In so far as homophobia and drug use reflect social factors, individual interventions will be unlikely to alter them, although they have the potential to ameliorate their effects. If the causes of new infections do not remain solely at the individual level, individual level interventions are unlikely to address them. ${ }^{19-21}$ However, even major community level interventions may not explicitly attempt to shift the balance of power or alter other social forces which may cause new infections.

\section{HOW MUCH PREVENTION DO WE NEED?}

The choice of individual based or population based strategies cannot be separated from the issue of the scale of effort needed to reduce new infections. ${ }^{20}$ Individual level interventions often are very expensive and it is unlikely that in a high prevalence area individual counselling could be carried out at a scale and intensity great enough to affect the epidemic's course.

Finally, the success of individual focused interventions relies on attracting those individuals at high risk. These are often the individuals with the least motivation to participate and the hardest to attract. Upstream interventions may be more important in later phases of the epidemic, because those individuals with the highest risk levels and most resistance to change will be less inclined to attend or participate in interventions. Nevertheless, they may avert even more interventions in the earlier stages of the epidemic, particularly where there are high incidence and prevalence rates.

\section{THE MULTIPLE FORCES THAT PROMOTE PROFESSIONALISATION AND ONE ON ONE INTERVENTIONS}

Many forces contributed to the rise and fall in community involvement and an increase in one on one interventions. It is important to understand these forces if we are to make strategic decisions about which interventions to choose at different stages of an epidemic. Interviews with key participants and educators show that these factors result in the gradual abandonment of community mobilisation strategies and their replacement by less controversial, service oriented programmes. They include the decreasing severity of the threat posed by HIV; the difficulty of maintaining the community's focus on prevention; basic bureaucratic tendencies present in almost all organisations, including a decreasing willingness to take risk; the difficulty in mobilising a community for prevention; the competition for resources brought about by care and support activities; internalised and external homophobia; and pressures to be accountable to funders. I will describe each of these forces below, with examples of how they manifested themselves in gay community mobilisation efforts.

\section{Severity of the threat}

The late 1970s were marked by huge rates in sexually transmitted diseases (STDs), as described above, but the level of social response to them was almost non-existent. As San 
Francisco's major gay newspaper's editor would reflect just a few years later, at the beginning of the AIDS epidemic:

\begin{abstract}
"Time after time we've beaten the rap with infectious diseases (or so we thought). Gonorrhea was only clap. And syphilis was only VD. And hepatitis was only time for house rest (even for a third time). And scabies and crabs were a temporary annoyance, as were anal warts and herpes." (Lorch, 198322)
\end{abstract}

The health department was reluctant to conduct awareness campaigns within the gay community so as not to fan the flames of homophobia, and the community exerted no pressure on the health department to do anything at all about STDs. HIV, in fact, has created a heightened awareness of STDs, resulting in heightened vigilance and demand for public health response that would not have existed 20 years ago (O'Malley P, 2000; personal communication).

After 15 years of equating AIDS and death, the Vancouver conference in 1996 also heralded the advent of new treatments. The decreasing threat in HIV has not only led in some instances to higher rates of unprotected sex, but to a crisis in volunteerism as well. Boston and Seattle's AIDS prevention programmes both report fewer volunteers, and are turning to paid peer educators (Bonne D, 2000; personal communication; Byrnes B, 2000; personal communication).

\section{The difficulty of mobilising a constituency and volunteer base for prevention}

The first efforts for AIDS prevention-as well as the biggest behavioural change-were prompted by gay organisations, institutions, and activists, many of whom had no experience in public health. These included gay Democrats, gay doctors, and even gay male nuns. These efforts did not respond to a community plan, or any plan, and took place during the first phase of the epidemic when incidence was highest and prevalence rates skyrocketed.

Three gay leaders published a cry to action in the local gay newspaper, the Bay Area Reporter, in 1983. ${ }^{23}$ They wrote:

" . . There are those who insist on believing that there is no relationship between AIDS and sexual contact. (. . .) And we have decided not to be passive victims of this epidemic, to take steps to protect ourselves by making serious changes in our sex lives. We have stopped going to baths and similar places. We have greatly reduced the number of our sexual partners."

The San Francisco AIDS Foundation's early programmes were remarkable in that they emphasised maintaining community roots while explicitly rejecting one on one interventions:

"Given the urgency of behavior change, the educational strategy would focus more on changing community norms and on developing peer-support for lower-risk behaviors, than on changing individual behavior. All educational interventions would be designed as two-way communication devices where possible so that information would be obtained from the audience and well (sic) as being transmitted to the audience, providing a feedback loop that keeps the foundation in touch with the audience's current opinions, beliefs and needs. Marketing and selling, rather than more traditional academic models, would be used." (Research and Decisions Corporation. Memo to San Francisco AIDS Foundation and San Francisco Department of Public Health, 1984.)
By 1984, as the epidemic entered its decline, new infections tapered off, new diagnoses of AIDS were peaking, and formal planning was just beginning. The first city plan for HIV prevention clearly emphasised a high level of community involvement, stating that gay men, "representing those with the most to gain by ending the epidemic, would have principal responsibility for the overall campaign . . AIDS Prevention thus becomes a city-wide civic effort, involving minimally the participation of hundreds of people." ${ }^{24}$

Community response during that phase was still strong, and in San Francisco the STOP AIDS Project would be an outgrowth of some of its energy. STOP AIDS, from its founding in 1984, used a community organising model, and its founders explicitly rejected formal health education theory. From the very beginning and in marked opposition to Weber's theory of organisations described below, the STOP AIDS project's founders intended to shut the project's doors after reaching a critical mass. During the next two years, fully 3500 participants ( $15 \%$ of the estimated gay male population) participated in its volunteer led workshops. The project ran with a small handful of staff, and almost 300 volunteers with high degrees of responsibility for recruitment, facilitating workshops, and supporting the administrative operations of the organisation. ${ }^{25-27}$ They provided much of the two way communications circuit between the community and the agency described above.

The years 1987-90 showed a marked decline in community activity. STOP AIDS shut down in 1987 when it became apparent that the community's interest was waning further, and infections decreased to $1 \%$.

The San Francisco AIDS Foundation continued its media campaigns, educational events, and hotlines. Many of these projects targeted the general community; others-such as "Bleachman"- targeted injection drug users. However, most of the community's efforts during this phase of the epidemic were focused on caring for the thousands of men who were sick and dying.

In 1990, as a direct result of studies which showed that gay men's risk behaviour appeared to be increasing, ${ }^{28}{ }^{29}$ the STOP AIDS project reopened its doors. It was readily apparent that unlike the mid-1980s, when fear and anxiety gripped the community, STOP AIDS would never resonate as deeply with the community.

The increasing ratio of those participants whom STOP AIDS volunteers invited to participate in workshops and volunteer for the project to those who participated provides a strikingly clear indicator of the difficulty of maintaining ongoing community interest in prevention once incidence diminished. In 1990, outreach volunteers needed to approach and recruit some 5200 individuals in order to have 1200 attend their peer led workshops. By 1995, volunteers had to approach and recruit approximately 8000 men to attract the same number of workshop attendees.

Volunteer roles in HIV prevention have ranged from low involvement, with relatively little autonomy (that is, clerical tasks) to developing workshops, designing outreach strategies, and serving on boards of directors. (There are almost no data available regarding the use of volunteers in prevention, as distinct from care and support services. Most accounts blur the distinction.)

In many agencies, as tasks became more complicated, there was a growing recognition of the need for staff simply to maintain the day to day operations in a way that volunteers could not accomplish efficiently or on a large enough scale (Kessler L, 2000; personal communication). Also, as it became more evident that prevention was not simply a matter of handing out information and required a greater understanding of multiple and often complex psychosocial issues, many opted for more intensive interventions which often required more professionals. 


\section{Self perpetuation}

The sociologist Max Weber demonstrated how the main goal of many bureaucracies almost inevitably becomes self perpetuation and isolation from the community, regardless of whatever task they purport to accomplish. ${ }^{30}$ Community based organisations in many fields, including HIV prevention, have often fallen into the same trap. When making decisions, only rarely do an organisation's leaders consider "zero sum" solutions or closing down their organisation as an option, ${ }^{31}$ even though it may have outlived its purpose.

The more an agency is focused on its own survival, the less likely it is to take risk and to focus on service modalities. Early in the epidemic, agencies used conflict to their advantage. ${ }^{32}$ The San Francisco AIDS Foundation, for example, embraced the bathhouse conflict in the early 1980s as a media advocacy tool, and not long afterwards embraced conflict when the US Marines protested the Foundation's use of the marine insignia which one of the models-an ex-marine himself-had tattooed on his arm. Later, though, when the bathhouse issue resurfaced in the late 1990s, the Foundation stayed away from the issue altogether.

Outside attacks have made agencies more risk aversive. Extremist small groups of AIDS denialists in San Francisco disrupted community forums and assaulted AIDS organisation leaders, ${ }^{33}$ which had an important chilling effect on many organisations. Agencies needed to simultaneously attempt to keep themselves open to the community while providing security, which resulted in creating more barriersand perceived barriers - to community participation and ownership in prevention efforts.

\section{The competition for resources: treatment, care, and support}

One early San Francisco AIDS activist said, "This community sure is good at helping people die. Too bad it's not very good at helping people live." (Cusic C, 1987; personal communication.) Professionalisation and the development of a "service mentality" may have happened more in HIV than in other fields of public health because the needs of those who were HIV positive quickly became a higher priority for the community (Wallerstein N, 2000; personal communication). With a skyrocketing infection rate a few years later, it is not surprising that by the late 1980s the need for support took precedence over prevention.

With few exceptions, most AIDS prevention agencies are housed within organisations that also provide care. It is difficult to maintain the kind of organisational agility and the independence necessary for agencies to work with both "clients" in care programmes and "partners" in community level prevention programmes. Working with partners usually requires allowing for flexibility and shared authority which foster substantive decision making by volunteers and line staff. Client service programmes, on the other hand, typically require stricter protocols and clear lines of authority, which are often dominated by staff.

More volunteers donated their time to care than to prevention. ${ }^{67}$ Care and support activities are often tangible and well defined, with measurable outcomes and appreciative recipients. For example, volunteers can count the meals they deliver, and clients readily thank them. It is impossible, however, for a volunteer to detect that their work has helped someone avoid infection; it is also unlikely that anyone will thank them for doing so.

In later phases of the epidemic, recruitment of volunteers became more difficult among both older and younger men; nonetheless, several volunteer leaders who had survived the first phases remain active to this day.

\section{Homophobia (internalised and external)}

One of the most significant challenges for many gay organisations has been maintaining their focus on gay men. In order to gain credibility among non-gay supporters, community members, and physicians, many organisations were reluctant to openly identify with the gay communities which had founded them. ${ }^{34}$

Ambivalence about airing the community's "dirty laundry" concerning ongoing risk behaviour to outsiders through large scale campaigns and the media hampered efforts further. Some activist groups, for example, expressly rejected any responsibility and blamed schools and the media for new infections. ${ }^{35}$ Many other gay men accepted responsibility for their own risk behaviours on an individual level, but did not join collective efforts for prevention.

Funders' pressure to be accountable and conservative Many observers have argued that government funding creates more accountability, and requires professionals to provide that accountability. It is difficult to maintain accountability to both the community and the government. The government requires evaluation and accountability; the community only rarely asks. Agencies tend to prioritise responding to those who ask, in the rarefied language of goals, objectives, and units of service.

Wrestling with gay identity, as described above, and the quest for funding are often intertwined. In cities around the country, funders found that some HIV agencies which historically considered themselves gay changed their mission and direction to attract more funding. Some began addressing communities of colour even though they had no track record-or involvement of the community-to indicate their ability to do so. ${ }^{36}$ Their willingness to do so also reveals just how far they had drifted from their original community.

One on one interventions are also relatively easy to plan, implement, and evaluate. Finally, they lend themselves well to complex governmental accounting systems, which in San Francisco explicitly favoured individual level interventions.

\section{THE EFFECT OF THESE FORCES ON INTERVENTION SELECTION}

All of these forces contributed to an increased professionalism and reliance on one on one interventions. At the San Francisco AIDS Foundation, for example, programme managers sought funding for prevention case management because it was a new alternative, but with little consideration of its potential impact on the epidemic as a whole.

In his studies of Canadian AIDS service organisations, Cain found little incentive for staff to develop an approach "that focuses on peer-led group meetings, self-empowerment, political mobilisation, or the redefinition of personal problems in social and political terms ... People affected with HIV infection have been transformed into 'clients', rather than equal participants in a joint struggle against the epidemic" (Cain, 1993 ${ }^{37}$ ). As AIDS becomes considered more of a chronic disease, "to the extent that prevention is discussed, the strategies proposed for most chronic diseases are thoroughly individualistic and rarely challenge the conditions of the production of disease." ${ }^{\prime 38}$

AIDS organisations' staff and volunteers present an interesting paradox. They are often aware of the need to address larger social factors, but are often unable to address them programmatically. Many of their programmes still focus on the one on one, and do not challenge the status quo. This dynamic is not unique to HIV prevention but is found throughout social services. Margolin writes of social work's increasing commitment to "the case-by-case, social workerto-client mode of helping identified with Mary Richmond (...) This conflicts with the practice and philosophy of social work's central icon, the social reformer and founder of Hull House, Jane Addams. My point is that social workers may claim Jane Addams as their source of inspiration, but they do Mary Richmond." ${ }^{\prime 1}$ 


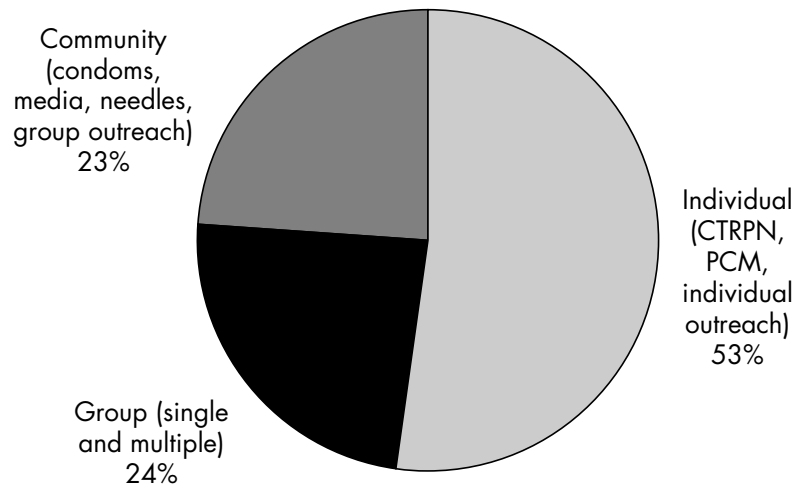

Figure 2 San Francisco HIV interventions in 1997.

\section{THE CURRENT BALANCE OF INTERVENTIONS}

In San Francisco and in other cities, an assessment of the current balance of interventions reveals mixed results in attempts to maintain a balance of interventions. In San Francisco, the local HIV prevention planning council analysed that the \$10 000000 in city contracts were divided, as shown in fig 2. (This notably does not account for direct funding from the Centers for Disease Control for community based agencies nor for funding spent by agencies with multiple programmes. ${ }^{39}$ Thus, while it appears that counselling, testing, referral, and partner notification (CTRPN) and individual interventions are still heavily funded, it is not currently possible to determine the city-wide balance of interventions.)

The San Francisco AIDS Foundation spent approximately $\$ 1000000$ of its $\$ 18000000$ budget on prevention in the financial year 2000-2001, divided as follows: prevention case management, \$250 000 (250 men $\times 14$ hours each); workshops and outreach, $\$ 440000$ (900 gay men); media, \$300 000 (Durazzo R, 2000; personal communication).

STOP AIDS spent approximately \$1.8 million in the year 2000 on outreach and recruitment for 7000 men, small group workshops and community forums for approximately 1500, neighbourhood organising and media.

\section{A SHIFT UPSTREAM}

In Boston, the largest agency, AIDS Action Committee of Massachusetts, took what may be the first step to try to make explicit shifts of their balance away from individual and to community level interventions. Currently, $28.7 \%$ of their budget is spent on primary prevention. Formerly, $44 \%$ of this was spent on individual and group level interventions. The organisation's prevention budget is now divided as in fig 3 .

\section{IMPLICATIONS FOR PRACTICE AND RESEARCH}

The gay male experience in HIV prevention is unique in that it brought so many resources to bear on its behavioural issue. If we accept that the level of resources dedicated to HIV prevention is insufficient, even among this relatively affluent community, then it makes sense for AIDS agencies not to try to be the sole providers of those resources but instead to develop partnerships within the public and private sector.

AIDS agencies themselves have to refuse to accept all responsibility for their communities and mobilise others to get involved. Despite the numerous obstacles, these are teachable skills. ${ }^{40}$ By rejecting complete adherence to provider and client roles and asking each individual at each step of a prevention intervention (one on one counselling, outreach, workshops, and forums) what they can do not only for themselves but for others, agencies can mobilise additional resources. Moving further upstream and to higher units of analysis, if we help identify the benefits to the private sector of further involvement there is potential to harness additional resources as well from businesses.



Figure 3 AIDS Action Committee, Boston, Massachusetts, 1999.

Although there are numerous protocols for individual and group level work, which are two of the important components for mobilising, there are relatively few available on how to carry out mobilisation efforts. Maintaining a peer nature and trying to infuse a professional sensibility are not inconsistent and are being practised in places around the country ${ }^{41}$ (Interrante J, 2000; personal communication). Training should be developed and implemented to promote and support these skills further. The very concrete and specific act of writing objectives provides a useful wedge to encourage programmes to move upstream. For example, by writing objectives which measure the number of community leaders invited to participate rather than predetermining their activity before submitting a grant, organisations may increase community members' ownership of activities.

Evidence also suggests that agencies will get what they ask for. Providing settings for community members where roles are very finite and lend themselves well to easily measurable tasks will attract volunteers who will carry out those tasks very well. However, there is evidence to suggest that when they offer community members more flexibility and autonomy agencies can attract those volunteers who seek, and will thrive in, such admittedly somewhat messy and difficult to measure settings. ${ }^{42}$ These volunteers may very well be more willing to advocate change for both individuals and the social conditions that may affect the course of the epidemic.

Funders should require evidence of organisations' claims that they are, in fact, "community based." Asking for letters of commitment and support from volunteers, the private sector, and other partners would help funders assess if these agencies are truly in touch with their community and working with community members rather than simply being located in a non-governmental setting.

There is a significant role for researchers to play as well. The efficacy of autonomous, organic, collective self mobilisation has not yet been studied, although there is ample evidence that the initial gay male mobilisation around HIV prevention, rather than the organised efforts which succeeded it, were strongly related to the most dramatic behaviour change. These mobilisations involve complex evaluation issues and lend themselves more to observational epidemiology rather than evaluation effort-to the extent that community level interventions are truly successful, they should not affect just the individuals participating directly in the intervention but the entire community. ${ }^{18}$

Taking a cue from Susser, there is a major role for all sectors in public health towards building a "purposeful social movement."43 Letting the "easy to measure" and "easy to implement" have primacy allows scientific and operational rigor to 
outstrip social and epidemiological relevance. In community intervention trials, secular trends profoundly affect the net results. This has been the case in both nutrition and smoking trials. The challenge to practitioners is to replicate and indeed accelerate these trends.

Even though rates of unprotected sex are climbing, with accompanying rates of incidence, it is highly unlikely that we will ever see a return to the large numbers of partners with whom men report unsafe sex, or the high level of infections in the early 1980s that played such an important role in mobilising individual and social change in the gay community. Thus expecting another "natural experiment" to emerge spontaneously, on the same scale as that of the early 1980s, is highly unlikely.

Nevertheless, epidemiologists would do well to keep a careful track of these events, both those occurring within organisations and those that take place around (or even in opposition to) them. Letters to the editor, news articles, the opening and closing of baths and sex clubs, the onslaught of pharmaceutical advertisements-all activities taking place outside AIDS organisations-may play an indirect but important role, and arguably have an impact on behaviour as great as or greater than those carried out by agencies themselves. Epidemiologists should track them. Epidemiologists can also work with community based organisations to assess the degree to which they reach the community, and the degree to which individuals perceive their importance, as they make their decisions about individual behaviour.

There are significant forces at work which encourage professionalisation and a reliance on one on one interventions. There are similar challenges facing epidemiologists and funders. Nevertheless, the history of AIDS prevention among gay men shows that community mobilisation is possible and brings with it additional resources. It would be overly optimistic to expect a return to the high level of activity of the early 1980s, but it would be defeatist to assume that the status quo is a given, and that we can't do better. In particular, the area of structural and environmental interventions, which can reinforce safe behaviour when community interest in collective action wanes, provides a potential area for prevention workers, researchers, and funders alike.

\section{ACKNOWLEDGEMENTS}

I thank the staffs at the UC Berkeley School of Public Health Library and San Francisco Public Library for assistance with archives, and the many individuals who gave generously of their time for interviews. Robin Bunton, Roy Cain, John Potterat, and Joe Wright gave extensive and thoughtful comments. This paper is dedicated to Chuck Frutchey (1953-2000), volunteer and director of education at the San Francisco AIDS Foundation, President of the Board of Directors of the STOP AIDS Project, and an architect of San Francisco's AIDS prevention efforts.

\section{REFERENCES}

1 Shilts $\mathbf{R}$. And the band played on: politics, people, and the AIDS epidemic. New York: St Martin's Press, 1987.

2 Winkelstein W, Wiley JA, et al. The San Francisco men's health study: continued decline in HIV seroconversion rates among homosexual/ bisexual men. Am J Public Health 1988;78:1472-4.

3 Sorensen G, Emmons K, et al. Implications of the results of community intervention trials. Annu Rev Public Health 1998:19:379-416.

4 Sweat $M$, Denison J. Reducing HIV incidence in developing countries with structural and environmental interventions. AIDS 1995;9(suppl);251-7

5 Valdiserri RO, Robinson C, et al. Determining allocations for HIV-prevention interventions: assessing a change in federal funding policy. AIDS Public Policy J 1997; 12:138-48

6 Wohlfeiler D. Structural and environmental HIV prevention for gay and bisexual men. AIDS 2000;14(suppl 1):S52-6.

6a San Francisco Department of Public Health. Quarterly AIDS surveillance report March, 2000. San Francisco: San Francisco Department of Public Health, 2000

7 San Francisco Department of Public Health. The San Francisco Department of Public Health and AIDS Research Institute/UCSF response to the update estimates of HIV infection in San Francisco, 2000.

8 Quimby E, Friedman SR. Dynamics of black mobilization against AIDS in New York City. Social Problems 1989;36:403-15.
San Francisco Department of Public Health. HIV consensus report. San Francisco: San Francisco Department of Public Health, 2001.

10 Winkelstein W, Samuel M, et al. The San Francisco men's health study. III. Reduction in human immunodeficiency virus transmission among homosexual/bisexual men, 1982-86. Am J Public Health 1987;77:685-9.

11 Osmond D, Page K, et al. HIV infection in homosexual and bisexual men 18-29 years of age: the San Francisco young men's health study. Am J Public Health 1994;84: 1933-7.

12 Katz MH. AIDS epidemic in San Francisco among men who report sex with men: successes and challenges of HIV prevention. J Acquir Immune Defic Syndr Hum Retrovirol 1997;14(suppl 2):S38-46.

13 Centers for Disease Control. Increases in unsafe sex and rectal gonorrhea among men who have sex with men. MMWR 1999;48:45-8

14 McCusick L, Wiley JA, et al. Reported changes in the sexual behavior of men at risk for AIDS, San Francisco, 1982-84: the AIDS Behavioral Research Project. Public Health Rep 1985;100:622-9.

15 McCusick L, Coates T, et al. HTLV-III transmitting behavior and desire for HTLV-III antibody testing in San Francisco men at risk for AIDS 1982-1985. San Francisco: San Francisco AIDS Foundation, 1985:1-14.

15a Ekstrand ML, Stall RD, et al. Gay men report high rates of unprotected anal sex with partners of unknown or discordant HIV status. AIDS 1999; 13:1525-33

16 Carey MP. Prevention of HIV infection through changes in sexual behavior. Am J Health Promot 1999;14:104-11.

17 Blankenship K, Bray S, et al. Structural interventions in public health. Atlanta, GA: Structural Barriers and Facilitators for HIV Prevention [conference]: 22-23 Feb 1999

18 Friedman SR, O'Reilly K. Sociocultural interventions at the community level. AIDS 1997;11(suppl A):S201-8.

19 Bracht N, Kingsbury L. Community organization principles in health promotion. In: Bracht $\mathrm{N}$, ed. Health promotion at the community level. Newbury Park: Sage, 1990:66-88.

20 Decosas J, Pedneault V. Preventing sexually transmitted diseases through individual- and population-based public health approaches: social and political implications. J Infect Dis 1996;174(suppl 2):S248-52.

21 Minkler M. Personal responsibility for health? A review of the arguments and the evidence at century's end. Health Educ Behav 1999;26:121-40.

22 Lorch P. Gay men dying: shifting gears part I. San Francisco: Bay Area Reporter, 1983

23 Huberman $\mathbf{R}$, Jones $\mathrm{C}$, et al. Three gay figures join the AIDS debate. San Francisco: Bay Area Reporter, 1993.

24 San Francisco AIDS Foundation. A comprehensive AIDS education/prevention plan for fiscal year 1984-85. San Francisco: San Francisco AIDS Foundation, 1984.

25 San Francisco Department of Public Health AIDS Activity Office. Scope of work, San Francisco AIDS information and education program. San Francisco: State of California Department of Health Services, 1985.

26 San Francisco Department of Public Health AIDS Office. Program review of STOP AIDS project. San Francisco: San Francisco Dept. of Public Health AIDS Office, 1987

27 Wohlfeiler $\mathbf{D}$. Community organizing and community building among gay and bisexual men. In: Minkler $M$, ed. Community organizing and community building for health. New Brunswick: Rutgers, 1997:230-43.

28 Ekstrand ML, Coates TJ. Maintenance of safer sexual behaviors and predictors of risky sex: the San Francisco men's health study. Am J Public Health 1990;80:973-7.

29 Stall $\mathbf{R}$, Ekstrand $M$, et al. Relapse from safer sex: the next challenge for AIDS prevention efforts. AIDS 1990;3:1181-7.

30 Weber M. Bureaucracy. In: Gerth HH, Mills CW, eds. Max Weber: Essays in sociology. New York: Oxford University Press, 1946:196-244.

31 Margolin L. Under the cover of kindness: the invention of social work. Charlottesville: University Press of Virginia, 1997

32 Wolfred TR. Ending the HIV epidemic: a call for community action. In: Petrow S, Franks P, Wolfred TR. Ending the HIV epidemic: community strategies in disease prevention and health promotion. Santa Cruz: Network Publications, 1990:113-31

33 Beswick T. More violence from Act-Up SF: woman injured at HIV treatment forum. San Francisco: Bay Area Reporter, 30, 2000.

34 Cain R. Managing impressions of an AIDS service organization: into the mainstream or out of the closet? Qualitat Sociol 1994;17:43-61.

35 Gay and Lesbian Alliance Against Defamation. KRON-TV considers follow-up to HIV series. Update 1994; 1 .

36 Andriote J-M. AIDS service organizations and the gay community. AIDS Educ Prev 1995;7(suppl):91-5.

37 Cain R. Community-based AIDS services: formalization and depoliticization. Int J Health Serv 1993;23:665-84.

38 Fee E, Krieger N. Thinking and rethinking AIDS: implications for health policy. Int J Health Serv 1993;23:323-46.

39 HIV Prevention Planning Council. Addendum to the San Francisco HIV prevention plan. San Francisco: HIV Prevention Planning Council, 1998.

40 Minkler M. Community organizing and community building for health New Brunswick: Rutgers University, 1997.

41 Labonte R. Community development and the forming of authentic partnerships In: Minkler M, ed. Community organising and community building for health. New Brunswick: Rutgers University Press, 1997:88-102

42 Stewart E, Weinstein RS. Volunteer participation in context: motivations and political efficacy within three AIDS organizations. Am J Commun Psychol 1997;25:809-37.

43 Susser $\mathbf{M}$. Some principles in study design for preventing HIV transmission: rigor or reality. Am J Public Health 1996;86:1713-16. 